\title{
EVALUATION OF \\ A HYDROHANDLING SYSTEM \\ FOR SORTING AND SIZING APPLES FOR STORAGE IN PALLET BOXES
}

Marketing Research Report No. 948

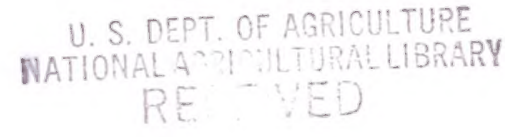

NOV 9 1977

PROCURFNTNT CECTION

CURRENT SERIAL RECORDS

\section{Agricultural Research Service \\ UNITED STATES DEPARTMENT OF AGRICULTURE \\ In Cooperation With}

Michigan State University Agricultural Experiment Station 



\section{Historic, archived document}

Do not assume content reflects current scientific knowledge, policies, or practices. 
This publication reports research involving pesticides. It does not contain recommendations for their use, nor does it imply that the uses discussed here have been registered. All uses of pesticides must be registered by appropriate State and/or Federal agencies before they can be recommended.

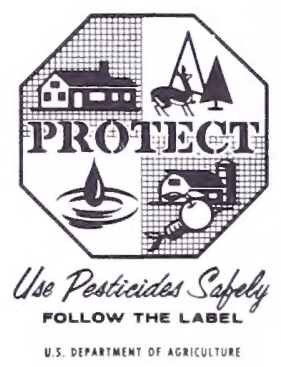

CAUTION: Pesticides can be injurious to humans, domestic animals, desirable plants, and fish or other wildlife-if they are not handled or applied properly. Use all pesticides selectively and carefully. Follow recommended practices for the disposal of surplus pesticides and pesticide containers. 


\section{ACKNOWLEDGMENTS}

The research on which this report is based was conducted by the Departments of Agricultural Engineering and Horticulture of Michigan State University of Agricultural and Applied Science under Contract No. 12-14-100-7791(52), as amended, with the U.S. Department of Agriculture.

Many individuals and companies contributed to this project. Much of the design work was done by Eudell Vis, graduate assistant, Department of Agricultural Engineering, Michigan State University, in cooperation with Fred Durand, Jr., President, Durand-Wayland Machinery Co., and his engineering staff. The equipment was manufactured by Durand-Wayland Machinery Co., Woodbury, Ga. The site and facilities for testing the hydrohandling system were furnished by the Belding Fruit Sales and Belding Fruit Storage Companies, Belding, Mich., through the courtesy of W. H. Braman, President. Installation and operation during the 1966 season was supervised by Mr. Vis.

Paul Bergdolt, graduate assistant, Department of Agricultural Engineering, Michigan State University, began working on the project in 1966 and continued through the spring of 1967. The content of his M.S. Thesis, "An Evaluation of a Prototype Apple Hydrohandling System," served as a basis for the economic analysis of this report.

Robert Schneider, graduate assistant, Department of Agricultural Engineering, Michigan State University, supervised operations during the 1967 season.

L. George Wilson, graduate assistant, Department of Horticulture, Michigan State University, was responsible for major portions of the apple handling and fruit evaluation studies conducted with the 1966 and 1967 crops.

Many other staff members of the Agricultural Engineering and Horticulture Departments assisted with this project; their help, together with that of the persons named above, is gratefully acknowledged.

Trade names are used in this publication solely for the purpose of providing specific information. Mention of a trade name does not constitute a guarantee or warranty of the product by the U.S. Department of Agriculture or an endorsement by the Department over other products not mentioned. 


\section{CONTENTS}

Summary Page

Introduction . . ........... 1

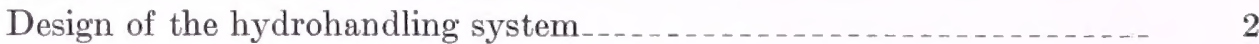

Summary of experiments with prototype hydrohandling system _...... 4

Costs of the prototype apple hydrohandling system _._.

Factors considered in the cost analysis $\ldots \ldots \ldots$

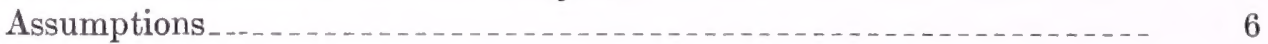

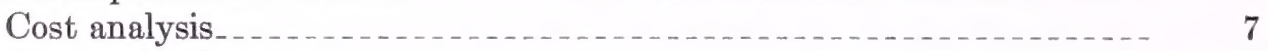

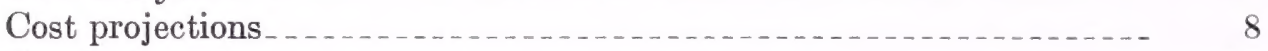

Conclusions_................ 10

Preliminary operational test and study of bruising $\ldots \ldots \ldots$

Capacity of the system _...

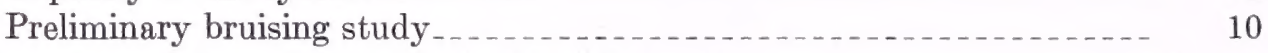

Performance of the prototype hydrohandling system _............... 11

Types of tests . . .

Commercial operations . . .

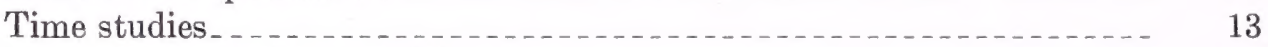

Uniformity of pallet box fill _............. 13

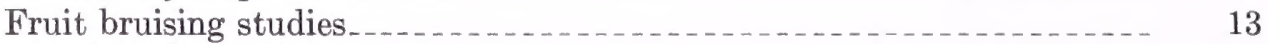

Examination of stored fruit (1966 crop)

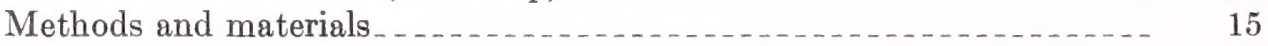

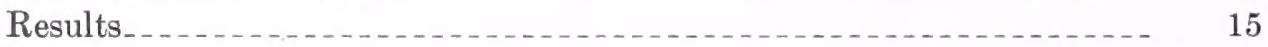

Discussion . . . .

Tests with 1967-crop apples... 16

Component tests... 16

Fruit handling

Fruit settling during storage

Fruit sizing .

Literature cited

Washington, D.C.

For sale by the Superintendent of Documents, U.S. Government Printing Office Washington, D.C. 20402 - Price 25 cents

Stock Number 0100-2454 


\section{EVALUATION OF A HYDROHANDLING SYSTEM FOR SORTING AND SIZING APPLES FOR STORAGE IN PALLET BOXES}

By D. H. DEwex, professor of horticulture, and B. A. STout, professor of agricultural engineering, Michigan State University; and Joseph F. HERrICK, JR., investigations leader, Transportation and Facilities Research Division, Agricultural Research Service

\section{SUMMARY}

A prototype hydrohandling system for sorting and sizing apples before storage was designed, constructed, and installed at a commercial apple packing and storage house. The system was based on completed research covering the development of a hydrohandling system for sorting and sizing apples for storage in pallet boxes. Following installation, the system was tested under commercial conditions to evaluate its performance. After initial tests, further modifications to the system were made and tested.

The system was designed to permit sorting, sizing, and filling apples back into pallet boxes at a rate of 600 bushels per hour. Test runs indicated that this volume of fruit could be handled by the system.

When used in a simulated commercial operation for about 35,000 bushels of apples, performance of the hydrohandling system was satisfactory, yet several limitations were apparent. The handling costs were 22 cents per bushel of fruit, of which 57.4 percent was for fixed charges. A net gain of 4 cents per bushel could have been realized by release of the storage space that would have been occupied by cull and utility grade fruit, provided all culls and utilities were removed by passage of the fruit through the system. Profitable use could be projected by consideration of volume, quality, variety of fruit, and of efficiency and operating rate of the equipment.

Fruit sizing varied in accuracy, with poor accuracy occurring whenever the underwater sizing chains carried a relatively large proportion of apples that should have passed through the chain openings. Uniform filling of the pallet boxes with sized and graded fruit was difficult to regulate and could be attained only by a skilled operator. Overfilling of the boxes resulted in excessive fruit damage by bruising, whereas underfilling required hand finishing to utilize the maximum storage capacity of the boxes.

Apples sampled during regular operating periods consistently showed that damage by bruising and skin breaks was relatively minor in comparison to the damage that resulted previously by harvesting, hauling, and dumping. Nonetheless, excessive damage was sometimes found upon removal of the fruit from long-term storage. Much of this was due to pressure bruising, which occurred because of flesh softening when apples improperly nested against each other during the hydrofilling operation. McIntosh apples were particularly susceptible to this kind of damage, whereas Jonathan and Delicious were not.

\section{INTRODUCTION}

Apples in many fruitgrowing areas are taken directly from orchards and stored in conventional refrigerated and controlled atmosphere (C.A.) storage. Modern developments in handling and storage have increased the potential benefits of sizing and sorting apples before storing them. 
The use of pallet boxes or bulk handling has increased not only the need for presizing and presorting, but also the difficulty of presizing and presorting due to possible damage to the fruit upon dumping and refilling the pallet boxes. ${ }^{1}$

In 1960, Pflug and Dewey $(8)^{2}$ were successful in using water as a medium for unloading apples. To learn more about the behavior of apples in water and to obtain design data for a hydrohandling system, a study was initiated in 1962 under a cooperative agreement between the Michigan Agricultural Experiment Station and the U.S. Department of Agriculture. Matthews (6) in 1963 and Dewey et al. (5) in 1966 presented the results of this study and suggested design details for a prototype apple hydrohandling system.

\section{Design of the Hydrohandling System}

The purpose of this hydrohandling system is to size and sort apples at a rate up to 600 bushels per hour before placing them in storage. The apples arrive from the orchard in pallet boxes and need to be sized, sorted, and returned to pallet boxes with a minimum of hand labor and bruise damage. The hydrohandling system was described in detail by Stout et al. (9) in 1966. The major components are a flotation dumper, a hydroeliminator, a roller sorting table, a hydrosizer, and two hydrofillers (figs. 1 and 2).

The flotation dumper consists of a tank of water and a mechanism to submerge pallet boxes of apples in this tank (fig. 3). An impeller pump with a capacity of 1,000 gallons per minute circulates the water and floats the apples away from the submerged pallet box toward the hydroeliminator. A surge area 15 feet long and 5 feet wide is provided between the submerging mechanism and the hydroeliminator.

The purpose of the hydroeliminator is to sep-

\footnotetext{
I Although this report uses the term "pallet boxes," these are variously referred to in different areas as bulk boxes, pallet bins, pallet containers, and bulk containers. Pallet boxes used for apples may hold 16 to 25 bushels and have approximate outside dimensions of 48 by 40 inches with an inside depth of 30 inches. The pallet boxes used in this study had a capacity of about 20 bushels.

${ }^{2}$ Italic numbers in parentheses refer to Literature Cited, p. 22 .
}

arate the apples smaller than $2 \frac{1}{4}$ inches in diameter from the system before they reach the sorting table (fig. 4). A moving sizing chain, 4 feet wide with hexagonal openings of $2 \frac{1}{4}$ inches in diameter, submerges all the fruit. The smaller apples float up through the sizing chain, are directed into a lateral flume by a current of water, and are then elevated out of the water by a flight conveyor and dropped into pallet boxes. The larger fruit continues under the sizing chain and returns to the water surface beyond the hydroeliminator.

A modified version of a conventional roller sorting table elevates the apples from the water, serves as a sorting table, and returns the apples to the water in the hydrosizer tank (fig. 5). This sorting table is 4 feet wide; the level sorting plane is 10 feet long and is divided into six lanes. The rollers on the sorting table are rubber covered, 21/4 inches in diameter, spaced on 3-inch centers, have a reverse roll to rotate the fruit, and are driven by a variable speed mechanism to provide a translation rate of 20 to 40 feet per minute.

Workers sorting apples stand on wooden platforms at the sides of the sorting conveyor. The defective fruits are placed on a utility and cull conveyor, which is a closed loop belt above the sorting table. The lower belt is for utility apples which are transferred from the belt to a conveyor and to a dry pallet box filler which places the apples in a pallet box. The cull apples are diverted from the cull belt to a gravity flow chute leading into a pallet box. Cull chutes were provided at the sides of the table to increase the capacity and efficiency of the workers.

The hydrosizer is much like the hydroeliminator except the chain size allows apples less than 3 inches in diameter to pass through (fig. 6). All apples are submerged by the chain, and the smaller ones float up through the chain openings and are directed into a lateral flume by water current. Apples 3 inches and larger in diameter continue under the sizing chain and return to the water surface in the main flume beyond the hydrosizer.

Two similar hydrofillers, one for each size of fruit, are used to return the fruit to pallet boxes. Each unit consists of a circular water tank, a submerging conveyor, two accumulators, a rotating rack, and a mechanical lift (fig. 7). Each tank is 10 

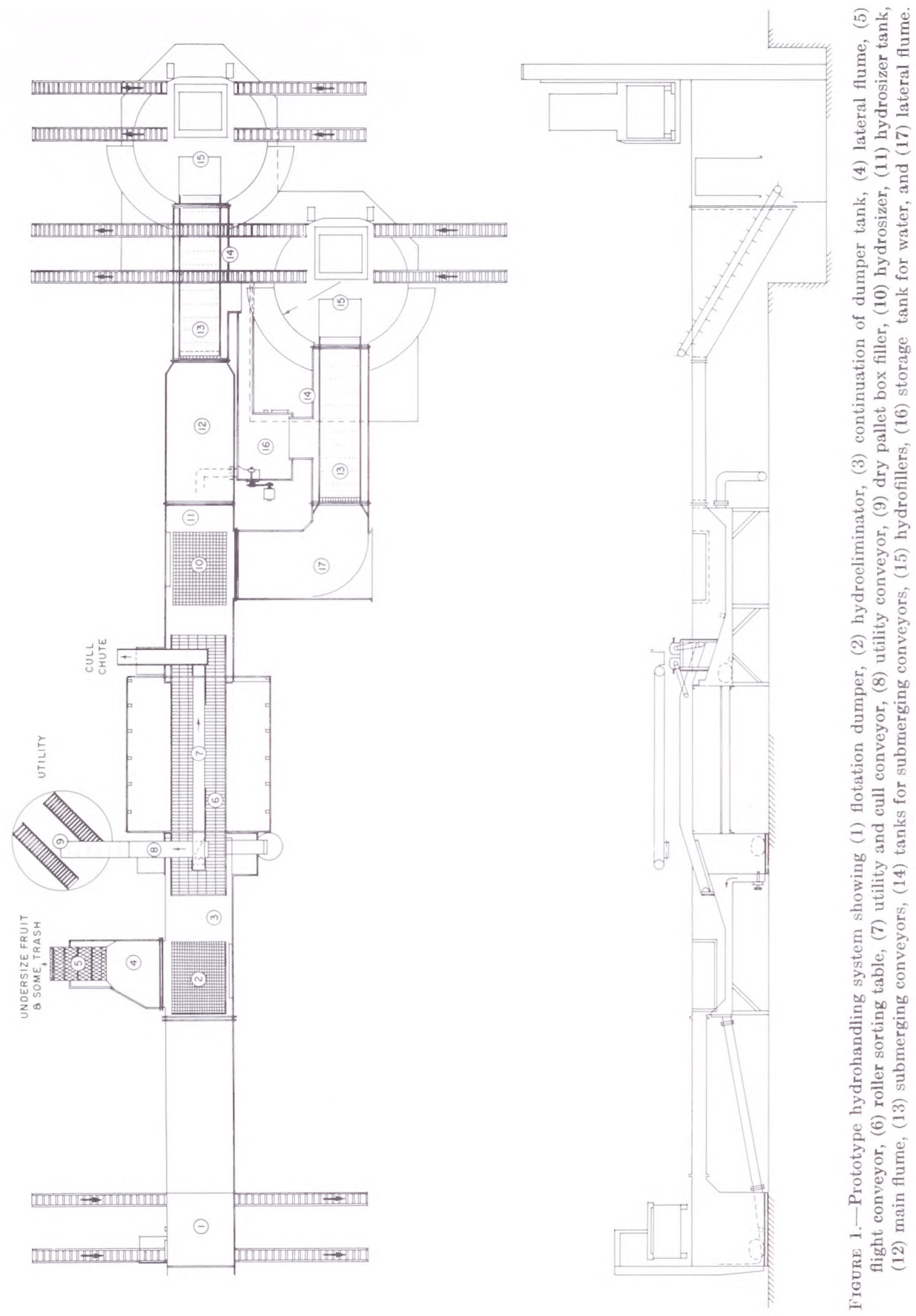
feet in diameter and 8 feet 10 inches deep. The submerging conveyor carries the apples down into the water and allows them to float up into the accumulators. Each accumulator is 36 inches wide, 44 inches long, 50 inches high, and has a capacity of 25 bushels. While in the tank, the accumulators rest on a frame mounted on a spindle that permits $180^{\circ}$ rotation.

The lift mechanism, similar to the lift on the hydrodumper, is mounted opposite to the submerging conveyor in the tank. This lift submerges a pallet box beneath the accumulator in the tank.

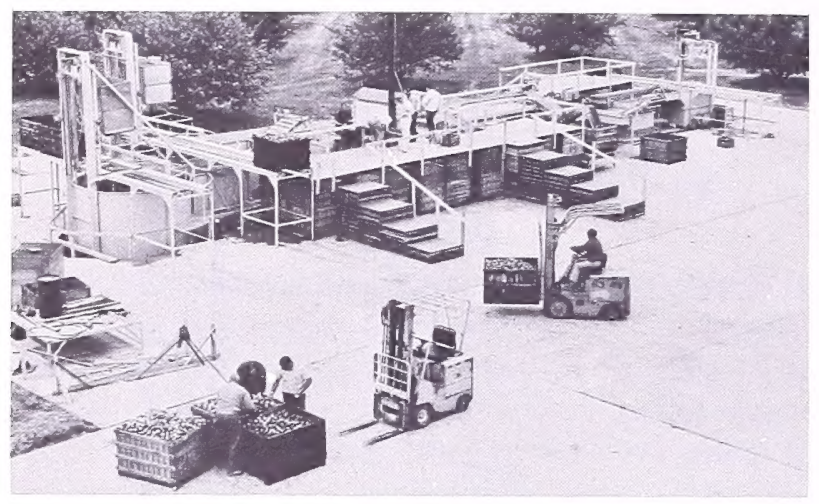

$\mathrm{BN}-27778$

Figure 2,-The prototype hydrohandling system. The platforms along the sides' were built for observation of tests.

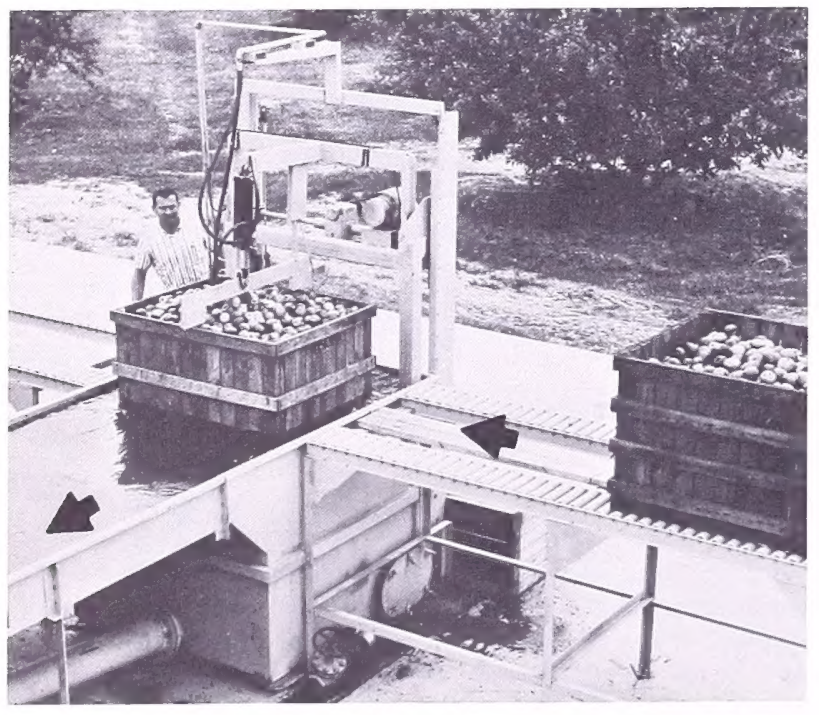

BN -27779

Figure 3.-A pallet box of tree-run (unsorted) apples being submerged by the flotation dumper.

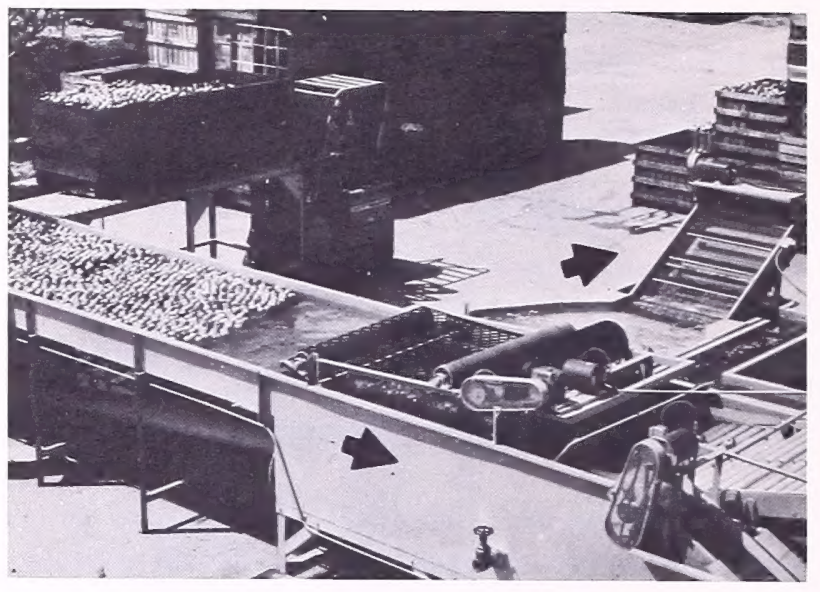

$\mathrm{BN}-27781$

Figure 4.-The hydroeliminator at the end of the flotation dumper tank.

The accumulator comes to rest on the rotating frame in the tank while the pallet box is submerged to the bottom of the tank. When one accumulator has been filled, the submerging conveyor is momentarily turned off while the accumulators are rotated $180^{\circ}$ on the rotating rack. With the empty accumulator positioned over the submerging conveyor, the conveyor is restarted. The filled accumulator is now over the empty pallet box. When the lifting mechanism raises the pallet box, it also lifts the filled accumulator and as the unit is removed from the water, the apples settle from the accumulator into the pallet box. At the top of the lift, the pallet box is in line with roller tracks and is rolled away as another box is rolled in to repeat the cycle.

One of the hydrofilling units was automated through the use of a hydraulic system to rotate the accumulators, and power rollers are used to move empty pallet boxes into position and filled boxes out of position. The other hydrofilling unit is manually rotated and boxes are positioned by hand.

\section{Summary of Experiments with Proto- type Hydrohandling System}

The system was designed in 1965, constructed by the Durand-Wayland Machinery Co., Woodbury, Ga., and installed at the Belding Fruit Storage Co. at Belding, Mich., in time for preliminary operational and bruising tests in May 1966. 


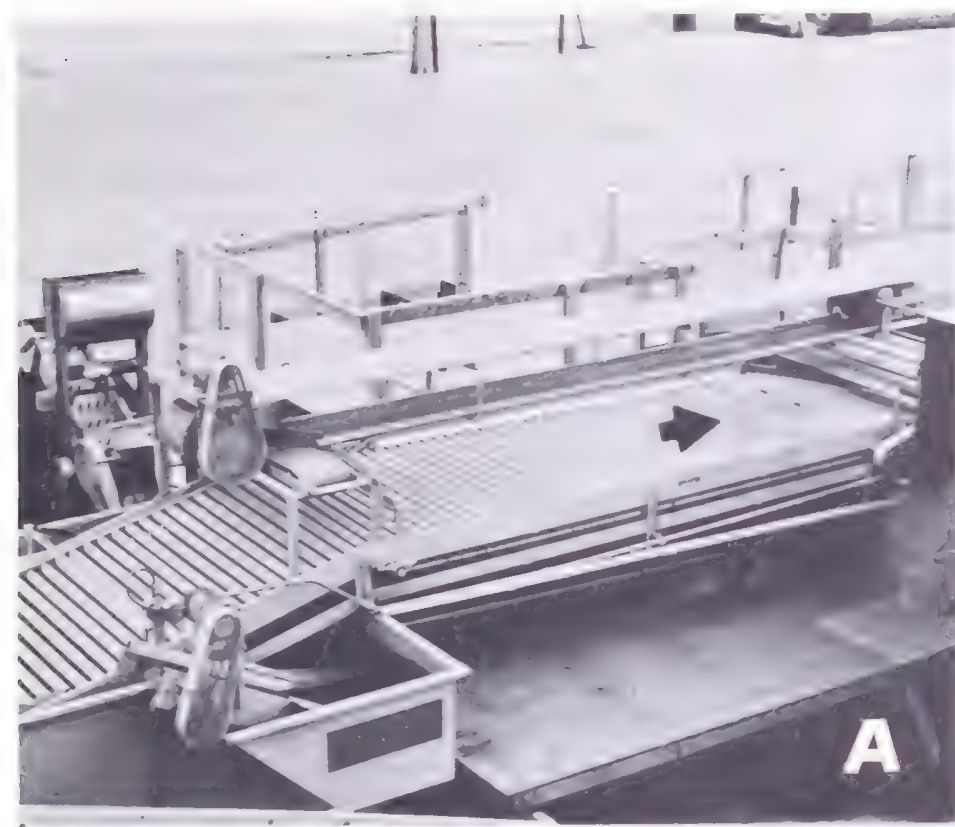

$13 \times-27783.3 \times-3753$

Figurf, 5.-(A) The roller sorting table (lanes were installed later) Utility apples are placed on lower belt above the table and are carried off by a cross-conveyor to a conventional dry pallet box filler (at left rear). Cull apples are placed on the upper belt and are diverted to a gravity chute (not visible in picture) at the end of the sorting table. (B) Cull chutes were added at sides of roller sorting table to increase efficiency of workers.

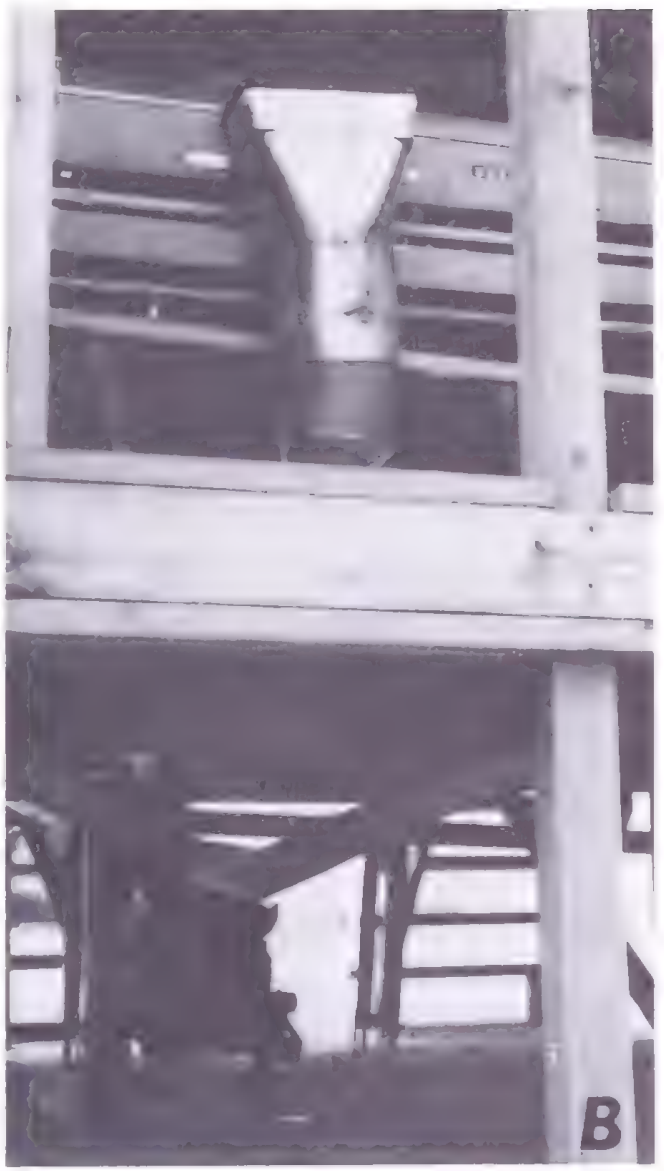

Commercial operation of the prototype hydrohandling system was begun on September 22,

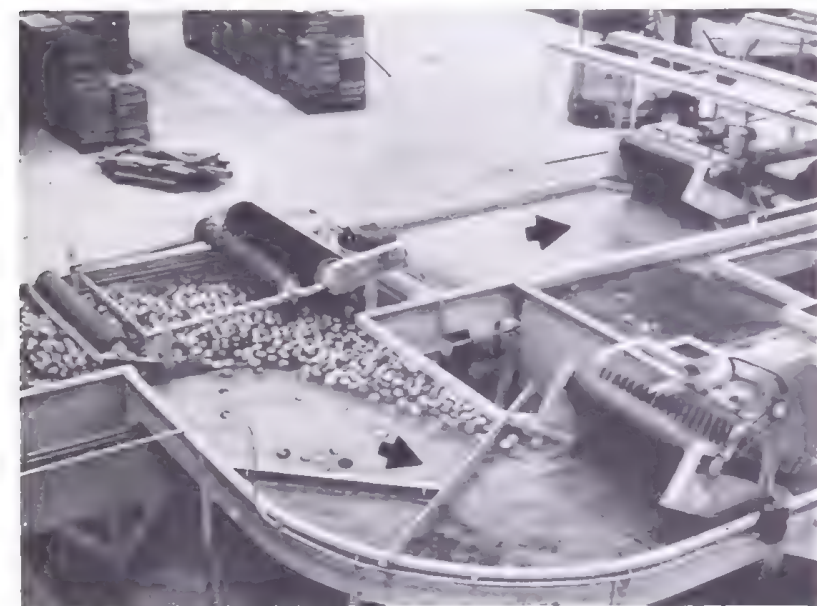

B) $>785$

Figure 6.-The hydrosizer. Apples are returned to water from the sorting table for separation into two sizes by the hydrosizer.
1966, and the system was in operation throughout the 1966 season. $\mathrm{Br}$ - Norember 9, 1966, a total of 35,554 bushels of fruit had been handled with the system. About 29 percent was remored as utility, cull, and cider apples, and the remainder was placed in storage.

Upon removal from storage in the spring of 1967, samples were taken from commercial lots and evaluated for bruises and other types of damage resulting from the hydrohandling operation. Because substantial damage was observed, the system was operated in the fall of 1967 on an experimental basis with much smaller quantities of fruit in an attempt to pinpoint the sources of damage.

A number of mechanical changes were made before the 1967 season to improve the system performance and reduce labor requirements.

Experimental lots from the 1967 crop were stored and evaluated for damage during the spring of 1968 . 


\section{COSTS OF THE PROTOTYPE APPLE HYDROHANDLING SYSTEM}

Observations were made under simulated commercial operating conditions during the 1966 season to obtain a general indication of the economic merits of the hydrohandling system. During a 7 week period, a total of 35,554 bushels of apples were run through the system. The limitations of an experimental machine and for a single season of operation must be realized when interpreting results. This work was reported in detail by Bergdolt (2) in 1968.

\section{Factors Considered in the Cost Analysis}

Expenses for the system can be separated into two categories, ownership costs and operating costs. Ownership costs can be subdivided into depreciation, interest on the investment, insurance, property taxes, and shelter (1). Operating costs include labor requirements, utilities, maintenance, repairs, and additional equipment.

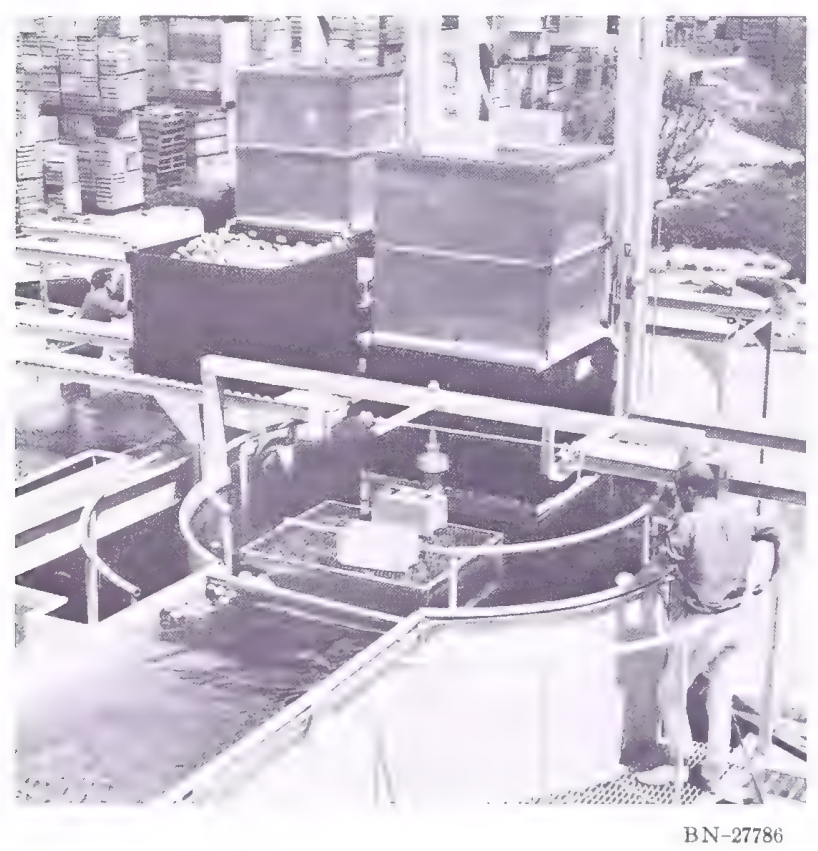

Figure 7.- The accumulator of the hydrofiller in the foreground is being filled with apples by the submerging conveyor. The second accumulator has been lifted from the water tank, together with a pallet box. The fruit is transferred to the box as it is raised above the water surface. (Grills and blocks were placed on the accumulators for testing.) A previously filled pallet box is shown to the left on a set of roller conveyors.
The use of the hydrohandling system is an additional operation that does not substitute for any later operation. If the system could be made to perform better, it might eliminate further resorting and resizing in preparing the product for market. Advantages of the system should accrue to the producer or owner of the apples. On the other hand, the storage operator would also profit from the system by charging a fee for prestorage sorting and sizing.

Profit, or net gain, from utilization of the hydrohandling system can be considered in two categories; both apply to storage costs. First, eliminating cull and utility fruit before storage will reduce storage costs, since the eliminated fruit does not increase in sale value sufficiently during the C.A. storage season to pay for the storage costs. Second, removing cull and utility apples permits the storage space to be used for U.S. No. 1 and better grade fruit, which will increase in sale value during C.A. storage and provide a higher return. This can be regarded as a potential gain associated with storage and is so considered in the following analysis.

\section{Assumptions}

Bainer (1) outlined a procedure for estimating the cost of owning and operating farm machinery. He suggested a straight-line depreciation schedule with a service life of 10 years and a salvage value of 10 percent of the initial cost. For a stationary machine such as a hydrohandling system, a 10year life is quite conservative for it is likely that the components would actually function longer. With a new type of machine, however, obsolescence may limit the useful life. Therefore, a useful life of 10 years was assumed.

Interest on the average investment was calculated at 6 percent. Insurance and taxes were assumed to be 1 percent of the initial cost as suggested by Bainer (1). Utility costs (electrical power and water) were based on current rates for utilities, $\$ 0.02$ per kilowatt-hour for electricity and $\$ 0.20$ per 100 cubic feet for water. The system is rated for 65 amps at 220 volts at full power, which is a requirement of $14.3 \mathrm{kw}$. per hour. The system has a water capacity of 20,200 gallons or 2,700 cubic feet. For cost estimating, it was 
assumed that the water was changed after approximately 20,000 bushels of apples.

The primary benefit of a prestorage sizing and sorting operation results from the increased value of the fruit that is actually placed in storage. Tuble 1 gives the magnitude of the increase in market value of fruit after C.A. storage as reported by Nichols ( $\gamma$ ) in 1965. These ralues, which ranged from $\$ 0.95$ to $\$ 1.34$ per bushel for quality fruit and $\$ 0.12$ to $\$ 0.38$ per bushel for cull and utility fruit, were used to calculate storage cost savings on culls and utility fruit and potential storage gain for U.S. No. 1 and better fruit. Based on Dalrymple's (4) study in 1956, a C.A. storage cost of $\$ 0.55$ per bushel was used.

TABLE 1.-Average price differential between fruit for sale at harvest and at time of removal from C.A. storage for three varieties of apples ${ }^{1}$

\begin{tabular}{|c|c|c|}
\hline Variety & Grade & $\begin{array}{l}\text { Price differ- } \\
\text { ential per } \\
\text { bushel }\end{array}$ \\
\hline & & Dollars \\
\hline MeIntosh.. & $\begin{array}{l}\text { U.S. No. } 1 \text { and better... } \\
\text { Utility. }\end{array}$ & $\begin{array}{r}\text { 1. } 34 \\
.17\end{array}$ \\
\hline Jonathan_ - . & $\begin{array}{l}\text { U.S. No. } 1 \text { and better... } \\
\text { Ctility. }\end{array}$ & 1. 38 \\
\hline Red Delicious_.... & $\begin{array}{l}\text { U.S. No. } 1 \text { and better.. } \\
\text { Utility }\end{array}$ & $\begin{array}{l}.95 \\
.27\end{array}$ \\
\hline All varieties... & Cull $\ldots$ & .12 \\
\hline
\end{tabular}

Average by Nichols (7) for 1961-1963 season.

\section{Cost Analysis}

\section{Ownership costs}

1. Depreciation - the total cost of the system was used including the price of the machine, facilities necessary to accommodate it, installation of utilities, installation of the machine, and incidental expenses incurred.

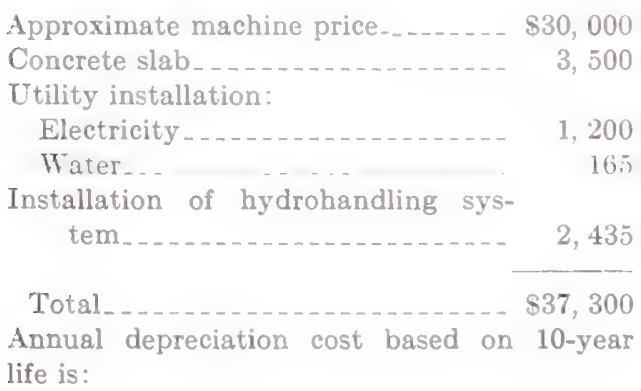

$$
\frac{\$ 37,300-\$ 3,730}{10}=\$ 3,360
$$

2. Arerage annual interest on investment Since:

$$
\frac{P i}{2}\left(\frac{n+1}{n}\right)=\text { average annual interest }
$$

(Where $P$ is inrestment, $i$ is interest rate, and $n$ is service life.)

Therefore:

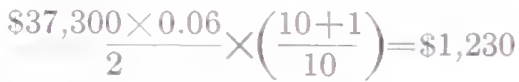

3. Insurance and property tax:

$$
0.01(\$ 37,300)=
$$

4. Shelter over sorting rolls:

$$
800 / 10=80
$$

Total fixed ownership. $1 \$ 5,040$

B. Operating costs

Labor. $2 \$ 3,030$

Utilities (118 hours of machine operation) electricity and water...... 40

Maintenance and repair........... 90 Additional equipment (3 lift trucks for 3 weeks at $\$ 60.00$ per week per (ruck)..

Total operuting co-t.

$\$ 3,700$

1 Cost per year including $\$ 3,360$ for depreciation.

${ }^{2}$ Labor costs are based on records of the cooperating commercial apple packing firm for operating system for 118 hours and handling 35,554 bushels of fruit.

C. Loss due to storage cost of utility and cull fruit Utility and cull apples do not increase in value adequately to cover the storage cost. Table 2 gives a summary of utility and cull fruit removed with the hydrohandling system during operations in the fall of 1966 and shows the loss that would hare been incurred had the same fruit been stored. The loss was calculated as the product of the number of bushels removed before storage and the net loss per bushel resulting if the poor quality fruit had been stored. The $\$ 3,538$ loss shown can be considered a saring attributable to the hydrohandling system if the cull and utility fruit were remored before storage and the same space used for storing premium quality fruit. 
TABLE 2.-Apples removed by use of hydrohandling system and loss if utility or cull fruit removed were placed in C.A. storage

\begin{tabular}{|c|c|c|c|}
\hline \multirow{2}{*}{ Variety and grade } & \multirow{2}{*}{$\begin{array}{l}\text { Amount } \\
\text { of apples } \\
\text { removed I }\end{array}$} & \multicolumn{2}{|c|}{ Loss if fruit were stored } \\
\hline & & Per bushel 2 & Total \\
\hline & Bushels & Dollars & Dollars \\
\hline \multicolumn{4}{|l|}{ McIntosh: } \\
\hline Utility _. . . _ & 2,516 & $0.55-0.17=0.38$ & 956 \\
\hline Cull _......... & 1,388 & $.55-.12=.43$ & 597 \\
\hline \multicolumn{4}{|l|}{ Jonathan: } \\
\hline Utility _..... & 551 & $.55-.38=.17$ & 94 \\
\hline Cull _........ & 2,511 & $.55-.12=.43$ & 1,080 \\
\hline \multicolumn{4}{|l|}{ Red Delicious: } \\
\hline Utility _........ & 1,060 & $.55-.27=.28$ & 297 \\
\hline Cull _........ & 1,196 & $.55-.12=.43$ & 514 \\
\hline Total _..... & 9,222 & & 3,538 \\
\hline
\end{tabular}

1 Based on data recorded by the cooperating commercial apple packing firm for apples removed during the sorting of 35,554 bu. of fruit.

${ }_{2}$ The loss per bushel is the difference between the charge for storing fruit ( $\$ 0.55$ per bu.) and the expected gain in value had the fruit been stored.

\section{Potential gain in storage space return}

Because high-quality fruit increases in value so as to more than offset the storage charges during C.A. storage, there is a potential gain in returns by utilization of the storage space for presized and presorted fruit instead of for tree-run (unsorted) apples. This gain was calculated as the product of the number of bushels removed and the net gain in value of apples during storage over storage cost of U.S. No. 1 or better quality fruit.

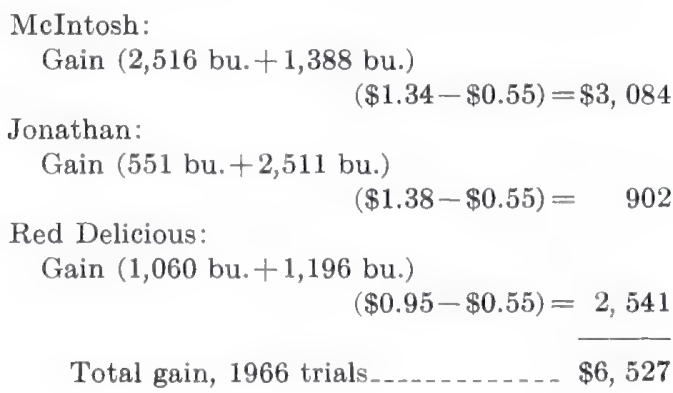

\section{E. Summation of 1966 operation}

For the operation of the system in 1966 with 35,554 bushels of McIntosh, Jonathan, and Delicious apples, the costs were:

\begin{tabular}{rr} 
Fixed ownership_... & $\$ 5,040$ \\
Operating_._._. & 3,700 \\
\hline Total_ _._. $\$ 8,740$
\end{tabular}

Accordingly, the cost per bushel of fruit put into the system was $\$ 0.25$.

The possible benefits in gross return gained through efficient utilization of storage as a result of eliminating the low quality fruit before storage include:

$$
\begin{aligned}
& \text { Elimination of loss due to the storage cost } \\
& \text { of utility and cull apples_. } \\
& \text { Increase in value of the U.S. No. } 1 \text { and bet- } \\
& \text { ter fruit stored in the space not used for } \\
& \text { utility and cull apples_. } \\
& \text { Total }
\end{aligned}
$$

This $\$ 10,065$ benefit offered a potential gain in gross return of $\$ 0.28$ per bushel for apples stored after presizing and presorting. When considered with the costs of owning and operating the hydrosystem, the possible net gain from sizing and sorting the fruit before storage in 1966 was $\$ 1,325$ or approximately 3.7 cents per bushel of fruit supplied to the system.

\section{Cost Projections}

The economic evaluation made by trial use of the presizing and presorting equipment in 1966 indicated that many variables must be considered to determine if the method could be economically justified. Bergdolt (2) subsequently conducted a computer analysis to consider a range of operating conditions and costs and to establish guidelines for profitable operation of the system. Six variables were considered. Those relating to crop conditions were volume of fruit handled, gradeout percentages as U.S. No. 1 or better, utility and cull qualities, and mixture of the three important varieties stored in Michigan. Machine and operating factors were varied according to investment cost, operating rate, and efficiency of the presizing and presorting operations. Representative results are graphically summarized in figures 8,9 , and 10.

The volume of fruit handled by the system produced the greatest change in net return; this is shown in all figures. Throughout the entire analysis, net return was negative when projected for an annual operating volume of 30,000 bushels. Consistently, the projected net return increases as the fruit volume passed through the system increases. Therefore, it would be necessary to have large volumes of apples available to efficiently 


\section{Conclusions}

A possible net gain was indicated as a result of prestorage sizing and sorting of 35,554 bushels of apples in a simulated commercial trial of the equipment in 1966. A theoretical analysis of the many variables affecting the net gain showed that not only must an adequate volume of fruit be utilized, but that the quality and variety of the apples must be previously assessed as to whether or not the sizing and sorting operation can be economically justified. Other important factors to consider are equipment cost, efficiency of sizing and sorting, and rate of operation.

\section{PRELIMINARY OPERATIONAL TESTS AND STUDY OF BRUISING}

After installation of the prototype hydrohandling system in the spring of 1966, operational tests were performed with each component to ascertain if it was functioning properly. Mechanical deficiencies were corrected and adjustments made as necessary.

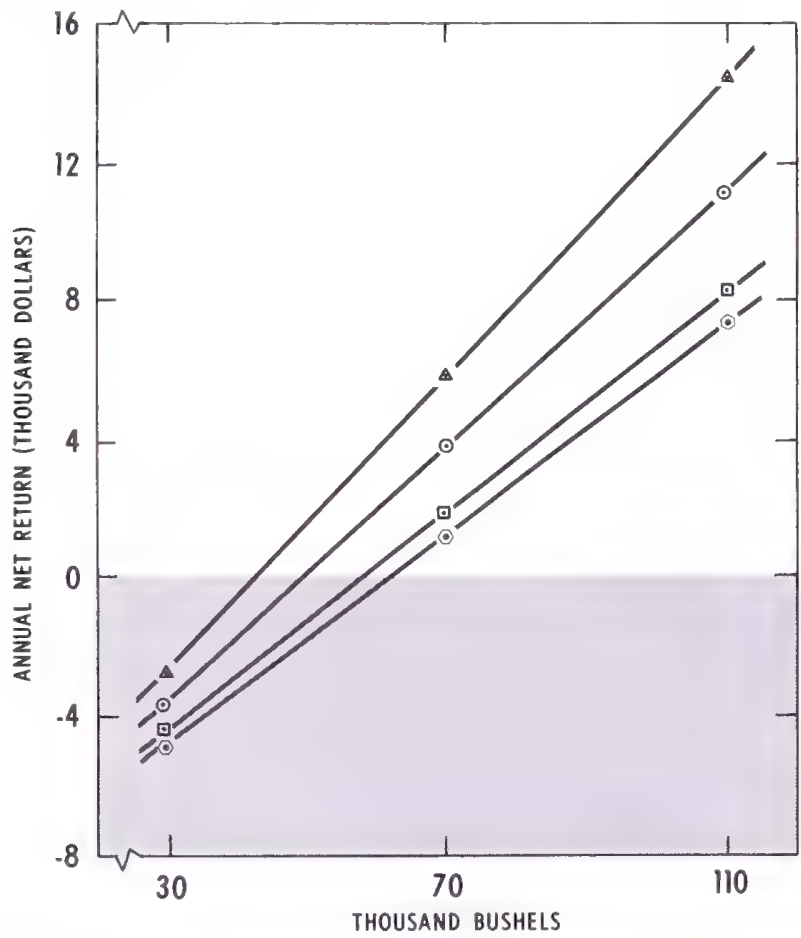

FIGURE 10.-The projected effects of mixture of varieties and total volume of fruit on annual net return from prestorage sizing and sorting of apples, with a sizing and sorting efficiency of 65 percent, a sortout of 70 percent U.S. No.1 or better grade, 20 percent U.S. Utility grade, and 10 percent culls, and a rate of 300 bushels per hour using equipment with an initial cost of $\$ 50,000$ Mixture of varieties, in percent:

$\begin{array}{crrr}\begin{array}{c}\text { Symbol on } \\ \text { figure }\end{array} & \text { Delicious } & \text { Jonathan } & \text { MeIntosh } \\ \text { O } & 25 & 30 & 45 \\ \text { A } & 0 & 50 & 50 \\ \text { } & 50 & 0 & 50 \\ - & 50 & 50 & 0\end{array}$

\section{Capacity of the System}

Test runs using Delicious and McIntosh apples were conducted to determine the system capacity. Each component was observed to determine if it was capable of performing its functions properly while the system was operating at full capacity. The maximum capacity of each component is difficult to establish because the quantity of fruit reaching one component is limited by those preceding it. The results in table 3 show that the design capacity of the system of 600 bushels per hour could be attained on a sustained basis. Limiting factors would include such things as breakdowns and excessive quantities of cull-out fruit.

TABLE 3.-Capacity checks on apple hydrohandling system, spring 1966

\begin{tabular}{|c|c|c|c|c|}
\hline Test & Time & $\begin{array}{l}\text { Number of } \\
\text { pallet boses } \\
\text { through system }\end{array}$ & $\begin{array}{c}\text { Equivalent num- } \\
\text { ber of pallet } \\
\text { boxes per hour }\end{array}$ & $\begin{array}{l}\text { Capacity } \\
\text { per hour }\end{array}$ \\
\hline & Minutes & Number & Number & Bushel \\
\hline $1 \ldots \ldots \ldots$ & 11 & 6 & 32 & 520 \\
\hline $2 \ldots \ldots \ldots$ & 35 & 16 & 27 & 440 \\
\hline $3 \ldots \ldots \ldots$ & 71 & 42 & 35 & 560 \\
\hline $4 \ldots \ldots \ldots$ & 57 & 41 & 43 & 680 \\
\hline $5 \ldots \ldots$ & 38 & 29 & 46 & 730 \\
\hline
\end{tabular}

${ }^{1}$ Assuming 16 bushels per pallet box.

\section{Preliminary Bruising Study}

Following the operational check, a preliminary study of fruit bruising was made to determine the feasibility of immediately employing the system on a semicommercial scale.

\section{Methods and procedures}

Bruise-free apples ranging in diameter from $2 \frac{1}{2}$ to $3 \frac{1}{4}$ inches were selected on May 12, 1966, from the top 10 inches of fruit in pallet boxes of McIntosh that had been in C.A. storage. Apples having two or three bruises, no greater than one- 
quarter inch in diameter, were selected, placed on molded fruit trays within cartons with the layers separated by foamed plastic pads, labeled, and returned to cold storage. On May 21, approximately 160 apples (100 small, 60 large) were assigned to three lots for placement into pallet boxes. The apples were spray painted with bronze florist paint for identification. The following treatments were made:

(1) Hand-filled pallet box with the bruisefree painted apples placed at random throughout (check).

(2) Hydrofilled pallet box of fruit of mixed sizes; the bruise-free apples were placed in the system at the surge area of dumper; all fruit were channeled to the "small fruit" filler by removal of the sizing chain.

(3) Hydrofilled pallet box of large apples (at least $2^{3 / 4}$ inches in diameter); same procedure as (2).

The pallet boxes were returned by lift truck to refrigerated storage until May 25 at which time the bruise-free apples were reclaimed by hand removal of all apples from the pallet boxes. The marked fruit were returned to trays, padded, and transported by car to East Lansing.

The test fruits were examined on May 26 and classified for bruising as none, slight, moderate, or serious according to the previously used standard reported in Marketing Research Report No. 743 (5). Fruit with stem punctures or other skin breaks were counted separately.

Pressure tests for flesh firmness were made with the Magness-Taylor tester with a 7/16-inch plunger at one pared check surface of 10 apples for each treatment after the final examination for bruising.

\section{Results}

The percentages of damaged apples after removal from the pallet boxes are given in table 4 .

Hydrohandling increased the bruising over hand filling. It caused approximately 30 percent of the test apples to be damaged excessively (moderate and serious bruising) as compared to only 6.8 percent for the hand-filled lot. This damage, however, could not be considered prohibitive because of the original poor condition of the test apples; they pressured 11.4 pounds at the time of the test as compared to a usual pressure of 18 to 20 pounds at harvest. It would appear that grading, sizing, and filling the bins in this manner caused less damage than would be normally expected for soft-fleshed apples.

Both of the hydrofilled lots of fruit had 25 apples with chain marks or narrow shallow bruises caused by contact of the apple with the links of the sizing chain. Several were considerably marked, probably because of rolling under the eliminator chain, particularly near the end of the run for a given bin. There were few stem punctures.

TABLE 4.-Damage to "bruise-free" apples due to handling and placement into pallet box

\begin{tabular}{|c|c|c|c|c|c|c|}
\hline \multirow{2}{*}{ Test } & \multirow{2}{*}{$\begin{array}{l}\text { Method of filling } \\
\text { pallet box }\end{array}$} & \multirow{2}{*}{$\begin{array}{l}\text { Stem } \\
\text { punc- } \\
\text { tures }\end{array}$} & \multicolumn{4}{|c|}{ Type of bruising } \\
\hline & & & Nono & Slight & Moderate & Serious \\
\hline & & Percent & Petcent & Peтcenl & Percent & Percent \\
\hline & $\begin{array}{l}\text { Hand filled } \\
\text { (check) }\end{array}$ & 1. 2 & 28. 0 & 65.2 & 5. 6 & 1. 2 \\
\hline & Hydrofilled & 1. 9 & 18. 2 & 56.0 & 19.5 & 6.3 \\
\hline $3 \ldots \ldots$ & __do_. & 2. 6 & 17. 3 & 48. 1 & 27.6 & 7. 0 \\
\hline
\end{tabular}

\section{PERFORMANCE OF THE PROTOTYPE HYDROHANDLING SYSTEM}

Commercial operation of the hydrohandling system was begun on September 22, 1966, at the Belding Fruit Storage Co. The system was operated throughout the harvest season as frequently as labor, fruit, and facilities permitted. The varieties used were mostly McIntosh, Delicious, and Jonathan, and a few Rome Beauty. The testing and evaluation of the system was conducted during periods of full operation of the equipment by personnel of the Belding Fruit
Storage Co. Operations ended on Norember 9, 1966.

\section{Types of Tests}

Economic considerations have been discussed previously. The performance tests dealt with engineering (or physical operations) and fruit quality factors.

Over 35,000 bushels of apples were hydrohandled during the 1966 season. Records of the Belding: 
Fruit Storage Co. were analyzed to obtain a general picture of the flow of fruit through the system.

Time studies of the various operations were made to determine labor and equipment required for moving the fruit through the hydrohandling system into storage.

In preliminary tests, the difficulty of obtaining uniformly filled pallet boxes from the hydrofiller was observed. A test was conducted to determine the extent of the problem.

Bruising is a major hazard in any prestorage handling operation. For a hydrohandling system to be successful, bruising must be minimized. A series of tests were conducted to identify and quantify the bruising problem.

\section{Commercial Operations}

Fruit came from many orchards to the hydrohandling system in regular pallet boxes. Enough boxes were accumulated to insure a long enough run to justify assembly of a crew. Because the equipment was new and relatively untested and the personnel were learning new jobs, many operational problems were encountered. Although this testing was conducted under commercial conditions, the data should be interpreted as an experiment.

The results of the commercial operation during the fall of 1966 are summarized in the following tabulation:

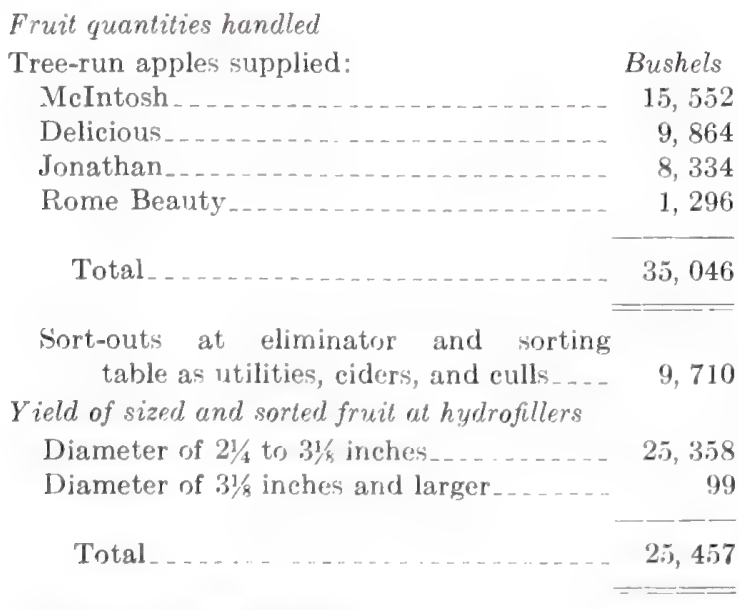

Overrun unaccounted for.

121

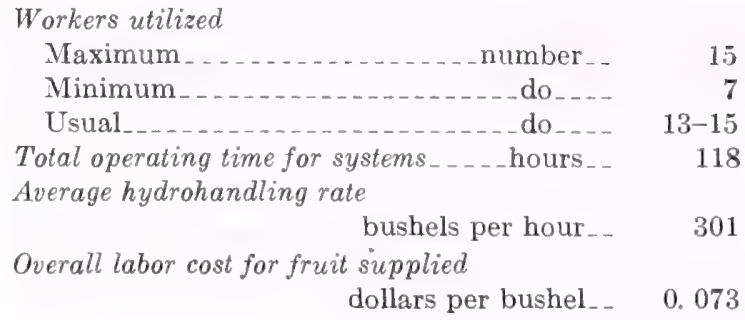

The actual operating rate averaged slightly above 300 bushels per hour. Preliminary system capacity checks (table 3 ) indicated much higher operating rates when the sorting operation was omitted. During sorting, it was often necessary to reduce flow rates to enable the sorters to remove an adequate amount of low-quality apples. Also, the actual operating rate reflects downtime due to equipment malfunction, as well as reduced operating rates while workers were learning their jobs.

Furthermore, because of their intermediate size this season, most of the apples were passed to only one filler unit, which sometimes limited the overall operating capacity of the system. As shown in the tabulation above, only 99 bushels of apples $31 / 8$ inches and greater diameter went to the filler, whereas 25,358 bushels were handled at the small fruit filler.

The most successful run from an operational standpoint reflects what the system should be ultimately capable of handling. It occurred on October 12 when 1,134 bushels of Delicious apples were hydrohandled in 2 hours, resulting in an operating rate of 567 bushels per hour. With a crew of 13 workers, this run resulted in a labor cost of 3.7 cents per bushel compared with the overall season average of 7.3 cents per bushel of fruit supplied to the system. In this run, all of the sized and sorted apples were returned to pallet boxes by one filler, thereby demonstrating the capacity of the filling unit.

The number of workmen was generally 13 to 15 . The maximum number was employed as follows: forklift operators, three; dumping, one; sorting, six; filling, two; leveling and labeling filled boxes, two; and supervising, one. The number was reduced to 13 by eliminating two women sorters; still further reductions were accomplished by using fewer sorters, one less person for leveling and labeling, and one less forklift truck operator. 


\section{Time Studies}

Operations were timed during actual working hours. These were broken down into elements, and an average time per element was determined. Observations included three forklift trucks, the dumper and filler operations, and the sorting table workers. The results are presented in table 5.

During normal operations, all three forklift trucks could keep ahead of their job assignments

TABLE 5.-Time required for various operations

\begin{tabular}{|c|c|c|c|}
\hline Element & Base time & $\begin{array}{l}\text { Fatigue } \\
\text { allowance } 1\end{array}$ & $\begin{array}{l}\text { Productiv } \\
\text { time }\end{array}$ \\
\hline \multicolumn{4}{|l|}{ Pallet boxes of fruit: } \\
\hline \multicolumn{4}{|l|}{ Unload from truck and } \\
\hline $\begin{array}{l}\text { move to temporary } \\
\text { storage }\end{array}$ & $\begin{array}{r}\text { Minutes } \\
0.95\end{array}$ & $\begin{array}{r}\text { Minutes } \\
0.06\end{array}$ & $\begin{array}{l}\text { Minutes } \\
1.01\end{array}$ \\
\hline \multicolumn{4}{|l|}{ Move from temporary stor- } \\
\hline age to dumper........ & .77 & .05 & .82 \\
\hline \multicolumn{4}{|l|}{ Empty fruit from pallet } \\
\hline boxes ............ & 1. 22 & .08 & 1. 30 \\
\hline \multicolumn{4}{|l|}{$\begin{array}{l}\text { Move filled boxes from hy- } \\
\text { drofiller to leveling }\end{array}$} \\
\hline 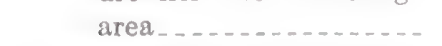 & .57 & .04 & .61 \\
\hline \multicolumn{4}{|l|}{ From leveling area to tem- } \\
\hline \multicolumn{4}{|l|}{ Empty pallet boxes: } \\
\hline \multicolumn{4}{|l|}{ Move from dumper to tem- } \\
\hline $\begin{array}{l}\text { Move from dumper to hy- } \\
\text { drofiller and return }\end{array}$ & 1. 0 & 0 & 1. 0 \\
\hline \multicolumn{4}{|l|}{ Pallet box dumping: } \\
\hline Lower box into wate & .17 & $\left({ }^{2}\right)$ & .17 \\
\hline$o x_{-\ldots}$ & 1. 22 & .08 & 1. 30 \\
\hline Raise empty box & .17 & $\left({ }^{2}\right)$ & .17 \\
\hline \multicolumn{4}{|l|}{ Raise hydraulic holddown } \\
\hline and remove empty box.- & .14 & .01 & .15 \\
\hline$x$ on lift $\ldots \ldots$ & .19 & .01 & .20 \\
\hline Lower hydraulic ho & .07 & .01 & .08 \\
\hline \multicolumn{4}{|l|}{ Hydrofilling: } \\
\hline $\begin{array}{l}\text { Raise lift to transfer apples. - } \\
\text { Remove full box and replace }\end{array}$ & .51 & (2) & .51 \\
\hline em & .2 & .02 & .26 \\
\hline Lower lift into & .4 & $\left({ }^{2}\right)$ & 4 \\
\hline Wait for accumulator to fill_- & 1. 88 & 12 & 2. 00 \\
\hline and rotate frame & .31 & .02 & .33 \\
\hline
\end{tabular}

${ }^{1}$ Fatigue allowance calculated as 6.3 percent of base time. Two 10-minute breaks bring total fatigue allowance up to 10 percent ( 8 ).

${ }^{2}$ Fatigue allowances not assigned to machine-dependent times. and were often idle waiting for work. The waiting times for the lift trucks given as a percentage of total time were as follows: 43.6 percent at the dumper, 49.9 percent at the filler, and 61.0 percent moving empty boxes from dumper to filler.

The reasons for idle time at the sorting table were for changing full utility fruit boxes, changeover of varieties, breakdowns, excess of apples at fillers, or insufficient flow of apples over the table.

Study made of the sorting table resulted in the following distribution of work time and idle time per hour:

\begin{tabular}{|c|c|}
\hline Element & Minutes \\
\hline Work & 43. 3 \\
\hline Idle.... & 16. 7 \\
\hline
\end{tabular}

\section{Uniformity of Pallet Box Fill}

A major problem in operating the hydrofilling component was the determination of the extent of fill of the accumulators. Much inconsistency in pallet box fill resulted. An underfilled pallet box results in wasted storage space, whereas an overfilled box can cause serious damage or spillage.

The fullness of a pallet box was determined by weight. An empty box was weighed, marked, and placed in the hydrofiller. After filling the pallet box was weighed again. Subsequently, the fruit were leveled in the box and apples added or removed as necessary, then the final weight was recorded before transport to storage. The results of the bin filling tests with Delicious and McIntosh varieties are given in table 6 .

Several methods, based on the buoyancy of apples, were tried to improve the uniformity of fill (2). No method was completely satisfactory because the specific gravity of apples varies slightly from one variety to another.

\section{Fruit Bruising Studies}

The primary interest at the time of fruit harvest was to immediately determine the possible damage caused by the hydrohandling system on fresh picked apples. For this purpose bruise-free apples 
Table 6.-Pallet box filling tests with Delicious and McIntosh apples

\begin{tabular}{|c|c|c|c|c|}
\hline Test & $\begin{array}{c}\text { Box } \\
\text { capacity } 1\end{array}$ & $\begin{array}{l}\text { Quantity of fruit } \\
\text { placed in box } \\
\text { by hydrofiller }\end{array}$ & Fill & $\begin{array}{c}\text { Adjust- } \\
\text { ment } \\
\text { necessary }\end{array}$ \\
\hline \multicolumn{5}{|l|}{ Deticious } \\
\hline 1 & $\begin{array}{r}\text { Bushels } \\
20.1\end{array}$ & $\begin{array}{l}\text { Bushels } \\
22.3\end{array}$ & 111 & $\begin{array}{r}\text { Pounds } \\
-93\end{array}$ \\
\hline 2. & 21.8 & 20.2 & 93 & +68 \\
\hline 3 & 20.5 & 18. 7 & 91 & +76 \\
\hline - & 22.1 & 22. 2 & 101 & -5 \\
\hline Average & 21.1 & 20. 9 & 99 & $\ldots$ \\
\hline \multicolumn{5}{|l|}{ McIntosh } \\
\hline $1 \ldots$ & 19.6 & 13. 9 & 71 & +245 \\
\hline $2 \ldots$ & 19.8 & 18.5 & 93 & +56 \\
\hline $3 \ldots$ & 19. 7 & 20.7 & 105 & -43 \\
\hline$\ldots$ & 19.6 & 18. 7 & 96 & +41 \\
\hline$\ldots \ldots$ & 20.2 & 20.1 & 99 & +5 \\
\hline$\ldots$ & 19.7 & 20.9 & 106 & -51 \\
\hline n & 19.3 & 18.4 & 95 & +41 \\
\hline - & 18. 8 & 18.8 & 100 & \\
\hline - n-_. & 19. 1 & 18. 8 & 98 & +11 \\
\hline $10 \ldots$ & 19.4 & 18. 0 & 93 & +60 \\
\hline $11_{\ldots}$ & 19. 7 & 18. 4 & 93 & +53 \\
\hline $12 \ldots$ & 19.1 & 17. 1 & 88 & +87 \\
\hline $13_{\ldots}$ & 20.2 & 16. 9 & 84 & +141 \\
\hline $14 \ldots$ & 19. 7 & 17.3 & 87 & +106 \\
\hline Average & 19.6 & 18. 3 & 93 & \\
\hline
\end{tabular}

${ }^{1}$ Determined from inside dimensions of each box.

were used in 14 tests; whereas, in another six tests, bruising was evaluated on the basis of changes that occurred in commercially handled samples selected throughout the system.

\section{Methods and procedures}

The bruise-free apples were selected in the orchard, carefully picked, and stored on padded trays in shipping cartons. They were painted with fluorescent red spray paint, dried, and immediately employed in an experiment. The apples were inserted and retrieved within the system during its use as a commercial operation, then evaluated for damage after several days of storage at $32^{\circ}$ to $40^{\circ} \mathrm{F}$. Bruising was classified subjectively for each fruit and indexed for numerical value (table 7).
Sample sizes varied from 30 to 172 apples, with 50 fruits being most commonly used. Pressure tests were made after the final examination for bruising with the $7 / 16$-inch tip of the MagnessTaylor tester. Apples with skin breaks were counted without regard to the bruising damage.

Tests conducted without bruise-free apples required sampling of the apples at the appropriate points to determine the possible increase in damage due to passage through one or several components of the system.

Sixteen tests were made with McIntosh, two with Jonathan, and two with Delicious apples.

\section{Results}

The entire harvesting and hydrohandling operation for presorting and presizing the apples resulted in bruise index values that never exceeded 2.0 , or, in other words, caused more than "slight" damage. No individual component of the system caused damage in excess of the "trace" classification employed in these tests.

The amount of skin breaks (4 to 6 percent of the apples), except for some lots of nonselected apples, was minor. Flesh firmness values for McIntosh during these tests were 14.9 to 18.8 pounds.

Jonathan and Delicious apples were relatively free of bruise damage that could be attributed to the hydrohandling equipment. Damage by handling through the system for "bruise-free" apples slightly exceed the "trace" amount. None of the apples received moderate or severe damage. Flesh firmness amounted to 18.7 pounds for Jonathan and 16.4 pounds for Delicious.

TABLE 7.-Descriptions and assigned values employed for apple bruising

\begin{tabular}{|c|c|c|c|}
\hline $\begin{array}{l}\text { Degree of } \\
\text { bruising }\end{array}$ & $\begin{array}{l}\text { Diameter of a } \\
\text { slngle brulse }\end{array}$ & $\begin{array}{l}\text { Diameter of an } \\
\text { aggregate of bruises }\end{array}$ & $\begin{array}{l}\text { Index } \\
\text { value of } \\
\text { bruising }\end{array}$ \\
\hline & Inch & Inch & \\
\hline None_... & $\ldots$ & Less than $0.5_{-}-$ & 0 \\
\hline Trace_._ & Less than $0.5_{-}$ & $0.5-0.75 \ldots$ & 1 \\
\hline Slight _... . & $0.5-0.75 \ldots$ & $0.76-1.0 \ldots$ & 2 \\
\hline Medium & $0.76-1.0 \ldots$ & $1.1-1.25 \ldots \ldots$ & 3 \\
\hline Severe_.... & $\begin{array}{c}\text { Greater than } \\
1.0 .\end{array}$ & $\begin{array}{c}\text { Greater than } \\
1.25 \text {. }\end{array}$ & 4 \\
\hline
\end{tabular}




\section{EXAMINATION OF STORED FRUIT (1966 CROP)}

Apples hydrohandled on a semicommercial basis in the fall of 1966 were disappointing in fruit quality, condition, and packout yield when removed from C.A. storage and prepared for market; therefore, hydrohandled apples were examined and compared with apples from the same orchard that had not been sized and sorted before storage. The apples had not been selected at harvest for poststorage examination, therefore, truly comparable treated and untreated pallet boxes could not be selected; however, all of the fruit was labeled for date of harvest and orchard as well as variety so that pallet boxes representative of handling procedures could be taken.

\section{Methods and Materials}

Apples grown in 1966 were removed from C.A. storage in March and April 1967. Five pallet boxes each of hydrohandled and nonhydrohandled MeIntosh and Delicious apples and four pallet boxes each of Jonathan apples were sampled. A sampling rack permitted the removal of the apples from one quadrant of the pallet box without disturbing the other apples. Samples consisted of 25 apples at the top, middle, and bottom of each pallet box. Each apple was immediately examined and classified for bruising, skin breaks, decay, and flesh firmness by the procedures described previously.

\section{Results}

The data expressed as percentages of damaged and decayed apples and values of bruising index and flesh firmness are summarized in table 8. Hydrohandling resulted in a slight increase in the percentage of McIntosh and Jonathan apples with moderate and severe bruises and a considerable increase for Delicious. A similar relationship occurred in the bruising index, which reflects the overall amount of bruising. Bruising at the top and bottom of the hydrohandled pallet boxes always exceeded damage at the middle. This would be expected at the bottom because of the weight pressure of the other apples. The great amount of
TABLE 8.-Condition of hydrohandled and tree-run apples removed from C.A. storage in March and April 1967

\begin{tabular}{|c|c|c|c|c|c|}
\hline $\begin{array}{l}\text { Variety, treatment, } \\
\text { and position } \\
\text { in pallet box }\end{array}$ & $\begin{array}{l}\text { Moderate } \\
\text { and severe } \\
\text { bruising }\end{array}$ & $\begin{array}{l}\text { Bruise } \\
\text { index } 1\end{array}$ & $\begin{array}{l}\text { Skin } \\
\text { breaks }\end{array}$ & $\begin{array}{c}\text { Fruit } \\
\text { rot }\end{array}$ & $\begin{array}{l}\text { Flesh } \\
\text { firmnes: }\end{array}$ \\
\hline
\end{tabular}

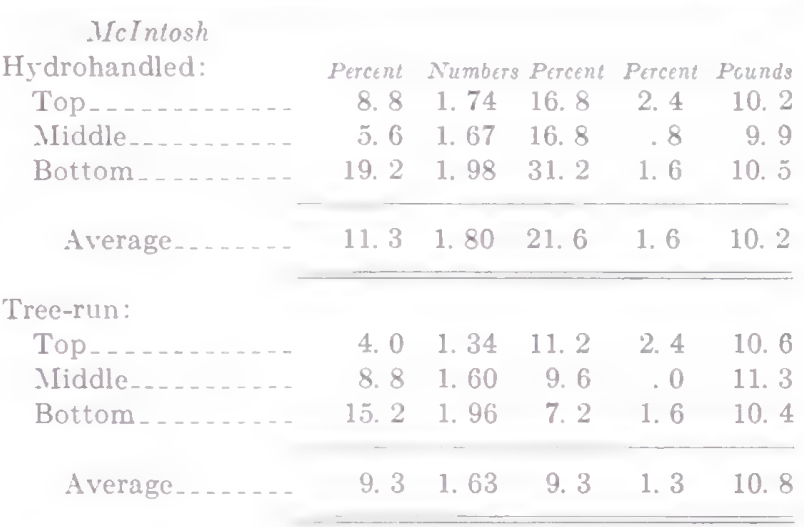

Jonalhan

Hydrohandled:

\begin{tabular}{|c|c|c|c|c|c|}
\hline Top & 14.4 & 1. 75 & 9. 3 & 3.4 & 12. 9 \\
\hline Middle__. & 8.5 & 1.63 & 3. 4 & 5. 1 & 12. 7 \\
\hline Bottom . . . . & 24.6 & 1. 89 & 8. 5 & 7. 6 & 11. 6 \\
\hline Average. & 15.8 & 1. 76 & 7. 1 & 5.4 & 12. 4 \\
\hline
\end{tabular}

Tree-run:

\begin{tabular}{|c|c|c|c|c|c|}
\hline Top_ & 15.2 & 1. 78 & 12.5 & 1.4 & 13. 0 \\
\hline Middle_... & 12. 5 & 1. 74 & 5.6 & 1. 4 & 13. 0 \\
\hline Bottom ........... & 13.8 & 1. 67 & 7. 0 & .0 & 12. 2 \\
\hline Average ........ & 13.8 & 1. 73 & 8. 4 & 9 & 12. 7 \\
\hline
\end{tabular}

Delicious

Hydrohandled:

\begin{tabular}{|c|c|c|c|c|c|}
\hline Top ....... & 5. 6 & 1. 34 & 3.2 & .8 & 12. 6 \\
\hline Middle _... & 1.6 & 1. 24 & 8 & .8 & 12. 7 \\
\hline Bottom .... & 8. 0 & 1. 46 & 4. 0 & 4. 8 & 12. 9 \\
\hline Average. & 5.1 & 1. 35 & 2.7 & 2. 1 & 1 \\
\hline
\end{tabular}

Tree-run:

$\begin{array}{llllll}\text { Top__._. } & 0 & 1.07 & 2.4 & 2.4 & 11.7\end{array}$

$\begin{array}{llllll}\text { Middle__. } & 8 & .94 & .0 & .8 & 12.2\end{array}$

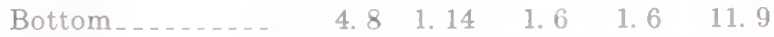

$\begin{array}{llllll}\text { Average } & 1.9 & 1.05 & 1.3 & 1.6 & 11.9\end{array}$

1 See table 7 . 
bruising at the top is attributed to the poor accuracy of fill, which required the addition or removal of apples to achieve a level fullness of the pallet boxes.

Skin breaks due to stem punctures and other mechanical injuries were considerably increased by hydrohandling for McIntosh and slightly increased for Delicious over tree-run apples. Jonathan skin breaks were affected only slightly by hydrohandling, but fruit rots were greatly increased. Hydrohandling, however, increased only slightly the amount of fruit rots for the other two varieties.

The firmness values indicate that the treatment lots within each variety were fairly compar- able in flesh texture and unaffected by hydrohandling.

\section{Discussion}

These observations indicate that fruit damage was increased by the hydrohandling treatment. Bruising of Jonathan was greater than for McIntosh, even though this variety is normally considered to be firmer and more resistant to bruising damage than McIntosh. Since many variables affect bruising and other damage, a critical evaluation of the effects of the system can be accomplished only with lots of fruit selected and treated under controlled conditions from harvest through storage.

\section{TESTS WITH 1967-CROP APPLES}

The excessive damage noted for hydrohandled apples upon removal from C.A. storage prompted the decision to omit further semicommercial trials of the system in 1967. Instead, small-scale experiments were made to determine possible causes of bruising and other mechanical damage and to pinpoint the sources of damage. They included tests of the individual components of the system, comparisons of apples stored tree-run and after bydrohandling, and examinations of settling in pallet boxes during the storage period.

\section{Component Tests}

\section{Methods}

Component tests were made with two runs of five pallet boxes each of McIntosh and a single run of five pallet boxes of Jonathan. A fourth trial with Delicious was started, but terminated after three pallet boxes were tested because of adverse weather. All fruits were picked in 1967 during the period of optimum maturity for long-term storage in nearby orchards (McIntosh, September 22 and 29; Jonathan, October 6; Delicious, October 13). The apples for each run were selected from a single orchard block, handled as separate pallet box lots, and treated within 1 day following harvest. The apples of a pallet box were dumped and passed continuously through the system into the accumulator, during which time samples of 100 fruits each were taken at random at the dumper tank, at the sorting table, and after passing through the sizer. After all apples of a bin had reached the accumulator, the equipment was stopped and the apples were removed from onequarter of the accumulator using a sampling rack.

One-hundred fruits were taken at random throughout the quadrant from top to bottom of the accumulator, the rest were returned to the accumulator. The filling operation was then completed by transferring the apples from the accumulator to the pallet box. The fruit in the quadrant of the pallet box opposite to that sampled at the accumulator were removed, and a 100-apple sample was taken from top to bottom. The apples of all pallet boxes were sampled in the same manner.

The apple samples were placed in molded pulp trays of 25 fruits capacity as they were taken from the system; four trays were placed in a polyethylene film-lined carton with plastic foam pads placed between each tray. The filled cartons were transported by car to East Lansing and stored at $32^{\circ}$ F. until examined during November and December, and again in mid-March, for bruises and other mechanical damage.

The evaluations for damage were made by one person in November and December and two persons in March. Each fruit was classified as "relatively free of bruising" or "bruised." The latter classification included all apples with moderate to severe damage according to previously used standards (5) and were considered unmarketable, according to U.S. Grade No. 1 standards, because 
of this damage. In addition, the apples were classified and counted as sound if free of injury, or damaged if injured by at least one skin puncture or break. Rotted fruits were counted and discarded at the first examination, then totaled with the rots of the second examination. The data were statistically examined using analyses of variance for the three runs of five pallet boxes that were completed.

\section{Results}

Fruit damage varied significantly by runs, but this was primarily a variety effect with McIntosh of runs 1 and 2 more seriously affected by bruising, skin breaks, and fruit rots than the Jonathan apples of run 3. There were significant increases in damage by bruising and skin breaks-but not by fruit rots-by the several components of the system. These are illustrated in figure 11. Large amounts of damage due to bruising were present on the apples as they were received and removed from the pallet boxes at the dumper. When examined initially in November and December and again in March, damage amounted to 25.9 percent and 32.7 percent, respectively. The greater amount] of bruising seen in March was due to additiona handling and, possibly, a more critical examination. In general, the results for components were similar at both inspections. By Tukey Test of the data, the bruising damage at the first inspection was significantly greater at the accumulator and in the refilled pallet box than at the dumper; at the second inspection, significant differences occurred only between the dumper and sorter and between the dumper and accumulator. Considerable bruising had occurred before initial sampling at the dumper due to harvesting, transporting, and dumping in these tests. The amount of damage that occurred within the system was relatively small in comparison to the initial amount. Consistent sequential increases by components as normally expected were either absent or obscured by variations between pallet boxes.

Skin breaks in fruit of the second run (McIntosh) exceeded those of the third (Jonathan) and fixst (McIntosh) runs by highly significant amounts. These apples averaged 14.6 pounds in flesh firmness, whereas the McIntosh of run 1 were 15.8 pounds and the Jonathan of run $3,18.5$ pounds. Significant differences (at the 5-percent level)

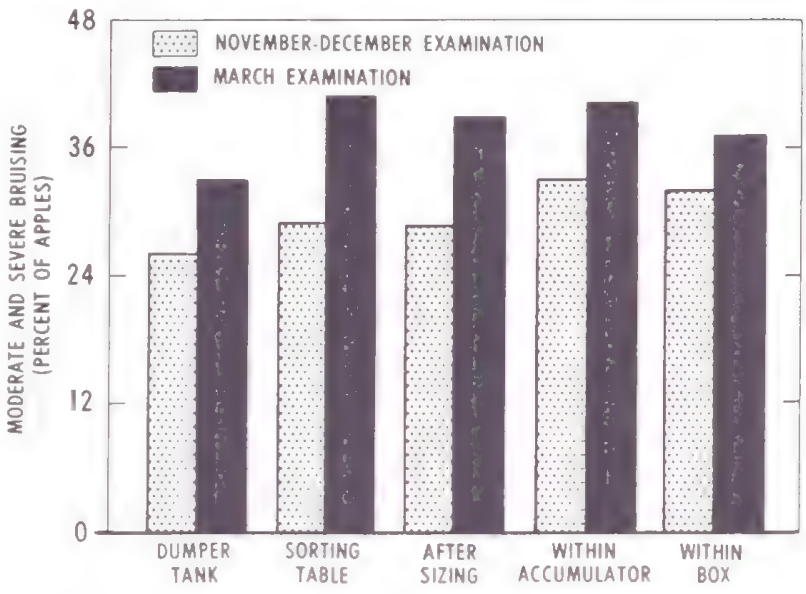

FrgURE 11.- Relative total bruising damage to apples removed from hydrohandling system at various points and held in cold storage in 1967-68.

occurred only between the dumper (6.2 percent damaged by skin breaks) and the refilled bin (9.2-percent damaged).

Fruit rots by March were 4.3 percent for run 1 (McIntosh), 7.4 percent for run 2 (McIntosh), and 2.0 percent for the Jonathan of run 3. Significant differences occurred only between runs 2 and 3. Fruit condition seemed to be a more important factor affecting rot than damage from skin breaks.

\section{Fruit Handling}

Comparisons were made of fruit damage, settling, and decay during long-term C.A. storage for apples stored tree-run (control), dipped in water (submerged), and passed through the hydrosystem (hydrohandled). Each handling treatment was subdivided into treatments with and without a scald inhibitor and fungicide drench treatment before storage.

\section{Methods}

Five pallet boxes each of McIntosh on September 28, Jonathan on October 5, and Delicious on October 6 were treated. The bins of each variety were selected from a single orchard block. The apples of the submerged handling treatment were covered with a wire mesh screen fitted to the top of the pallet box and then submerged with the bin remaining in an upright position in the water of the filling tanks so as to permit all apples to become buoyant within the 
bin. The apples were then removed and drained. The hydrohandled apples were run through the entire system without sorting and returned to bins at the hydrofillers. The controls were not dipped or handled. Five pallet boxes of each variety and handling treatment were stored without further treatment, whereas, another five pallet boxes of each were passed through the drench system used at the packing house for application of 1,000 parts per million diphenylamine (DPA) in a water solution as a storage scald inhibitor. This solution also contained captan at the rate of 0.66-pound of actual material per 100 gallons of water as a fungicide. The solutions were extensively used for other apples before being used for the experimental lots, and therefore, were probably high in disease organism content. The apples were stored immediately in commercially operated C.A. and cold storage rooms.

Damage to the fruit was assessed when the apples were removed from storage and prepared for marketing in late March to early April. Random samples of at least 100 fruits were taken by each of two persons from the hydrodumper tank after the apples were floated from the bins at the beginning of the sorting line, and rated as "free of bruise damage" or "bruised," using the moderate and severe standards as described previously. All fruit with decay were removed and counted.

\section{Results}

McIntosh apples were seriously damaged by bruising as a result of submerging and hydrohandling (fig. 12), whereas the Jonathan and Delicious apples were not. Damage to McIntosh by all of the treatments exceeded the corresponding treatments of the other two varieites by highly significant amounts. Control (untreated) McIntosh had approximately 16 percent of the fruit damaged by bruising; to this, the relatively careful submerging treatment in the enclosed pallet box increased the number of damaged apples by approximately 11 percentage points. The hydrohandling system causer an increase of 20 percentage points in bruising over the control so that over 36 percent were found to be damaged when the apples were dumped after removal from storage. The maximum percentage of bruised apples for Jonathan was 7.5 percent, for Delicious slightly less than 6 percent. For these varieties, there were no significant treatment differences.

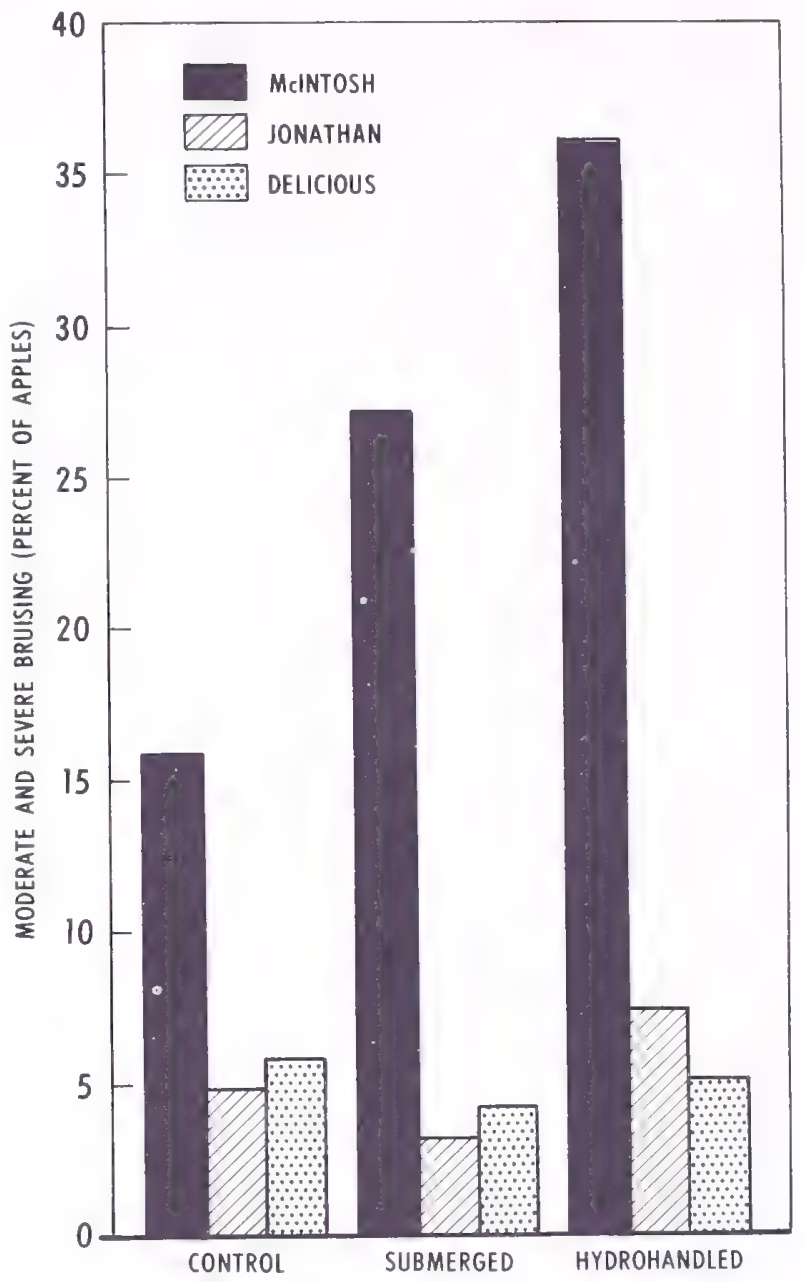

Figure 12,-Bruising damage to apples after C.A storage in relation to prestorage handling treatment and variety in $1967-68$.

Other tree-run and hydrohandled McIntosh apples, which had been treated and stored on September 19, were examined in March after C.A. storage for bruising according to vertical location within the pallet box. The fruit was removed by hand from one quadrant of the bin, and 97 to 174 apples examined and classified from the top, middle, and bottom of the pallet box.

The data (table 9), as was true for that of the previously described test, showed that hydrohandling greatly increased bruising. Here there was less than 10 percent of the apples with medium or severe bruising in the tree-run pallet boxes, whereas 22.4 to 28.2 percent of the hydrohandled 
critical than the experimental examinations. The yield of U.S. No. 1 McIntosh was considerably lower than for Jonathan and Delicious; however, it was not evident as to whether this was due to a lack of red coloration, fruit damage and defects, or other grade factors.

\section{Fruit Settling During Storage}

There were indications the previous season that fruit bruised during storage, probably upon aging as the flesh softened. To measure this possibility,

TABLE 10.-Packinghouse record of yield from experimental pallet boxes of apples

\begin{tabular}{|c|c|c|c|}
\hline \multirow[b]{2}{*}{ Variety and prestorage treatment } & \multicolumn{3}{|c|}{ Grade of sorted fruit dumped } \\
\hline & U.S. No. 1 & U.S. Utility & Cull \\
\hline \multicolumn{4}{|l|}{ McIntosh } \\
\hline Control: & Percent & Percent & Percent \\
\hline Without drench_ & 53.8 & 44.6 & 1.6 \\
\hline DPA + captan drench & 67.3 & 31. 1 & 1. 6 \\
\hline \multicolumn{4}{|l|}{ Submerged: } \\
\hline Without drench_ & 48. 7 & 49.7 & 1. 6 \\
\hline DPA + captan drench & 56.6 & 41.9 & 1.5 \\
\hline \multicolumn{4}{|l|}{ Hydrohandled: } \\
\hline Without drench. & 55. 2 & 43. 1 & 1. 7 \\
\hline DPA + captan drer & 50.8 & 46.9 & 2. 3 \\
\hline \multicolumn{4}{|l|}{ Jonathan } \\
\hline \multicolumn{4}{|l|}{ Control: } \\
\hline Without drench & 81.1 & 16. 7 & 2. 2 \\
\hline $\mathrm{DPA}+$ captan & 82. 2 & 16.7 & 1. 1 \\
\hline \multicolumn{4}{|l|}{ Submerged: } \\
\hline Without drench_ & 84.1 & 14. 8 & 1. 1 \\
\hline $\mathrm{DPA}+$ captar & 85.6 & 12.2 & 2. 2 \\
\hline \multicolumn{4}{|l|}{ Hydrohandled: } \\
\hline Without drench & 79. 3 & 17.4 & 3. 3 \\
\hline DPA + captan drench & 83. 2 & 15.6 & 1. 2 \\
\hline \multicolumn{4}{|l|}{ Delicious } \\
\hline \multicolumn{4}{|l|}{ Control: } \\
\hline Without drench... & 73.4 & 26.3 & .3 \\
\hline DPA + captan drench.- & 75.1 & 24.4 & .5 \\
\hline \multicolumn{4}{|l|}{ Submerged: } \\
\hline Without drench.. & 86.4 & 13.6 & 0 \\
\hline DPA + captan drench. & 70. 2 & 28.7 & 1. 1 \\
\hline \multicolumn{4}{|l|}{ Hydrohandled: } \\
\hline Without drench. & 75. 0 & 24.7 & .3 \\
\hline DPA + captan drench & 77.3 & 21.6 & 1. 1 \\
\hline
\end{tabular}

all pallet boxes of the above test were measured for fullness before and after storage. Settling was determined as the change in height of the fruit as measured at 20 points located by holes in two racks laid diagonally across a pallet box from corner to corner. McIntosh and Jonathan settled considerably, Delicious only slightly. Hydrohandling resulted in more settling than the other treatments; submerging caused no more settling than the control (table 11).

The "Variety $\times$ Handling" interaction was significant. Within varieties, hydrohandling had no effect on McIntosh, but hydrohandling significantly increased settling over the other two treatments for both Jonathan and Delicious. Within treatments, McIntosh settling exceeded Delicious settling for the control and submerged lots, but not for the hydrohandling treatment. Drenching did not affect settling.

Considering all varieties together, there was a highly significant correlation of bruising and settling, $\rho=0.37$; when evaluated separately, a significant positive correlation $(\rho=0.42)$ occurred for Jonathan, but not for the other two varieties. Rots and settling for all varieties were correlated, $\rho=0.427^{* *}$; individually by variety, they were McIntosh, $\rho=0.36^{*}$, Jonathan, $\rho=0.64^{* *}$, and Delicious, $\rho=0.53 * *$. The variety with the greater

\footnotetext{
* Significant at the 5-percent level.

** Significant at the 1-percent level.
}
TABLE 11. - Settling of apples in bins after handling treatment at harvest and during storage until spring

\begin{tabular}{lcccc}
\hline \multirow{2}{*}{ Varlety } & \multicolumn{3}{c}{ Handling treatment } & \multirow{2}{*}{ Mean * } \\
\cline { 2 - 4 } & Control & Submerged & $\begin{array}{c}\text { Hydro- } \\
\text { handled }\end{array}$ & \\
\hline & Centimeters & Centimeters & Centimeters & Centimeters \\
MeIntosh_-- & 2.7 & 2.1 & 3.2 & $2.7 \mathrm{a}$ \\
Jonathan_-- & 1.6 & 1.6 & 3.6 & $2.3 \mathrm{a}$ \\
Delicious _- & -.2 & .2 & 2.0 & $.7 \mathrm{~b}$
\end{tabular}

\footnotetext{
${ }^{1}$ Mean values not followed by the same letter are different at the 1-percent level of significance.
} 
amount of fruit rot (McIntosh) showed the least relationship of settling to rotting.

Flesh firmness values (table 12) of the apples before and after storage possibly explain the bruising differences noted for varieties. McIntosh and Jonathan had similar flesh firmness upon removal from storage and, also, similar settling values in the bins. Delicious came out of storage 3 pounds firmer in pressure than the other varieties and had less bin settling. Flesh firmness at harvest for McIntosh was 3.9 pounds less than for Jonathan and Delicious. These data suggest that the Jonathan, because of good firmness at harvest, nested against one another by slippage in the hydrohandled bins as they were placed into storage or shortly thereafter. Most of the settling reflected this nesting of the fruit, plus some with small pressure bruises upon subsequent softening. For McIntosh, we believe that the relatively soft flesh permitted little nesting through slippage, so that practically all settling resulted from the development of large pressure bruises where the fruit contacted each other at one or two points, rather than at the three or more points that occur with nesting during the dry filling of pallet boxes.

\section{Fruit Sizing}

Following the operation of the hydrohandling system on several occasions, the accuracy of the sizing components (eliminator and sizer) was checked with samples of fruit that had gone through the sizer without passing through the

TABLE 12.-Flesh firmness in pounds for apples at harvest and upon removal from storage in the spring

\begin{tabular}{lcc}
\hline \multirow{2}{*}{ Variety } & \multicolumn{2}{c}{ Time of measurement } \\
\cline { 2 - 3 } & Harvest time & After storage \\
\hline & Pounds & Pounds \\
MeIntosh_. & 14.6 & 12.5 \\
Jonathan & 18.5 & 12.5 \\
Delicious_... & 18.8 & 15.5 \\
\hline
\end{tabular}

chain openings. The results are summarized in table 13. Accuracy of sizing was determined by the relative quantities of apples that did and did not pass through the openings.

Relatively few of the apples employed in these tests were less than $2 \frac{1}{4}$ inches in diameter; consequently, the fruit did not compete or interfere much with each other while passing through the openings, and a good rate of accuracy was achieved. At the sizer, however, great quantities of apples had to pass through the openings (probably 80 percent of the McIntosh and 95 percent of the Jonathan). This overcrowding resulted in poor sizing efficiency. The effect of uniformity in size upon efficiency was demonstrated by reruns of Jonathan (table 13). When all apples that should have gone through the eliminator chain openings were run alone, only 75 percent passed through the chain. When all apples run through the 33 -inch sizing chain were less than $3 \frac{1}{8}$ inches in diameter, approximately the same amount (73 percent) passed through the openings. These results bear out the observations of the previous season that this style of underwater sizing is inefficient unless a small percentage of the apples present are small enough to pass through the openings, as would generally be true at the eliminator.

TABLE 13.-Sizing accuracy of hydroeliminator and hydrosizer components as percentage of properly sized fruits

\begin{tabular}{|c|c|c|}
\hline \multirow{2}{*}{ Variety and test number } & \multicolumn{2}{|c|}{ Component } \\
\hline & Eliminator: & Sizer ${ }^{2}$ \\
\hline MeIntosh: & Percent & Percent \\
\hline 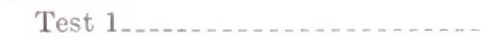 & 100 & 44 \\
\hline Test $2 \ldots \ldots$ & 100 & 45 \\
\hline \multicolumn{3}{|l|}{ Jonathan: } \\
\hline Test $3 \ldots \ldots$ & 100 & 30 \\
\hline Test $4^{3} \ldots \ldots \ldots$ & 75 & 73 \\
\hline
\end{tabular}

\footnotetext{
${ }^{1}$ Diameter, $2 \frac{1}{4}$ inches.

2 Diameter, $31 / 8$ inches.

3 Test 4 was a rerun of apples that had been similarly sized at either the eliminator or sizer in test 3 .
} 


\section{LITERATURE CITED}

(1) Bainkr, R., Krpner, R. A., and Barger, E. L.

1955. PRINCIPLES OF FARM MACHINERY. John Wiley and Sons, Inc., New York. $571 \mathrm{pp}$.

(2) Bergdolt, P. F.

1968. AN EVALUATION OF A PROTOTYPE APPLE HYDROHANDLING SYSTEM, M.S. Thesis, Mich. State Univ.

(3) Carmen, H. F., and Oldenstadt, D. L.

1964. THE CHANGING MICHIGAN FRESH APPLE PACKing industry. Mich. Agr. Expt, Sta. Res. Rpt. 23.

(4) Dalrymple, D. G.

1956. MARKETING CONTROLLED ATMOSPHERE Apples. Cornell Univ. Agr. Expt. Sta. AF 1028.

(5) Dewey, D. H., Stout, B. A., Matthews, R. H., Bakker-Arkema, F. W., and Herrick, Joseph F., $\mathrm{JR}$.

1966. DEVELOPMENT OF A HYDROHANDLING SYSTEM FOR SORTING AND SIZING APPLES FOR STORAGE IN PALLET BOXES. U.S. Dept. Agr. Market. Res, Rpt. 743, 31 pp, illus.
(6) Matthews, R. W.

1963. A HYDRO-HANDLING SYSTEM FOR PRESORTING AND PRESIZING APPLE FRUITS. M.S. Thesis, Mich. State Univ.

(7) Nichols, J. P.

1965. SOME ECONOMIC CONSIDERATIONS OF SORTING AND SIZING APPLES FOR BULK STORAGE. M.S. Thesis, Mich. State Univ.

(8) Pflug, I. J., and Dewey, D. H.

1960. UNLOADING SOFT-FLESHED FRUIT FROM Bulk Boxes. Mich. Agr. Expt. Sta. Quart. Bul. 43(1):132-141.

(9) Stout, B. A., Dewey, D. H., Vis, E. G., and Herrick, Joseph F., JR.

1966. A PROTOTYPE HYDROHANDLING SYSTEM FOR SORTING AND SIZING APPLES BEFORE STORAge. U.S. Dept. Agr. Agr. Res. Serv. ARS 52-14, 12 pp., illus. 

UNITED STATES DEPARTMENT DF AGRICULTURE

AGRICULTURAL RESEARCH SERVICE

BELTSVILLE, MARYLAND 20705

DFFICIAL BUSINESS

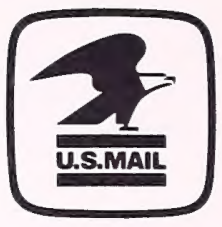

POSTAGE \& FEES PAID

United States Department of Agriculture 